\title{
Factors affecting successful esophageal foreign body removal using a Foley catheter in pediatric patients
}

\author{
Donghoon Lim', Jong Kun Kim', Yun Jeong Kim', Yeon Joo Cho', \\ Jae Wan Cho', Jungbae Park', Jae Young Choe', Byung-Ho Choe ${ }^{2}$ \\ 'Department of Emergency Medicine, Kyungpook National University School of Medicine, Daegu, Korea \\ ${ }^{2}$ Department of Pediatrics, Kyungpook National University School of Medicine, Daegu, Korea
}

Objective This study aimed to determine the factors that affect successful esophageal foreign body (FB) removal using a Foley catheter and to identify methods to increase the success rate.

Methods In this retrospective, cross-sectional study, we included pediatric patients who presented with esophageal FB impaction that was removed using a Foley catheter in the emergency departments of tertiary care and academic hospitals. We analyzed the effect of the patients' age, sex, and symptoms; FB type, size, and location; Foley catheter size; complications during FB removal; duration between $\mathrm{FB}$ ingestion and removal; operator's years of training; sedation; success rate of FB removal; endoscopy; and patient's posture during FB removal on the success of Foley catheter-based FB removal.

Results Of the 43 patients we enrolled, Foley catheter-based FB removal was successful in 81.4\% (35/43) but failed in 18.6\% (8/43) of patients; no FB-removal-related complications were reported. There was no significant association between the success rate of Foley catheter-based FB removal and any study variable. A higher number of years in training tended to increase the success rate of Foley catheter-based FB removal, although statistical significance was not achieved.

Conclusion Children's esophageal FB removal is a practical challenge in the emergency rooms, and using a Foley catheter is associated with a high success rate of the removal and low occurrence of complications. In this study, no single variable was found correlated with the success rate of Foley catheter-based esophageal FB removal in pediatric patients, which may indicate multiple variables interacting with one another to affect the success rate.

Keywords Foreign bodies; Foley catheterization; Endoscopy; Esophagus; Child
eISSN: 2383-4625

Received: 10 June 2020

Revised: 23 September 2020

Accepted: 12 October 2020

Correspondence to: Jae Young Choe Department of Emergency Medicine, Kyungpook National University School of Medicine, 130 Dongdeok-ro, Junggu, Daegu 41944, Korea E-mail: cjy@knu.ac.kr ORCID

https://orcid.org/0000-0002-4107-6621

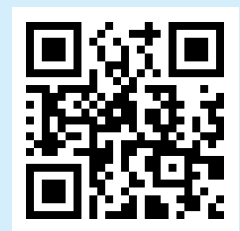

How to cite this article:

Lim D, Kim JK, Kim YJ, Cho YJ, Cho JW, Park J, Choe JY, Choe BH. Factors affecting successful esophageal foreign body removal using a Foley catheter in pediatric patients. Clin Exp Emerg Med 2021;8(1):30-36. https://doi.org/10.15441/ceem.20.070

This is an Open Access article distributed under the terms of the Creative Commons Attribution Non-Commercial License (https:// creativecommons.org/licenses/by-nc/4.0/). 


Capsule
Wummat is already known
Foley catheter-based esophageal foreign body (FB) removal is more time-saving and cost-effective than endoscopic FB
removal. The impaction of a FB in the upper or mid-esophagus, presentation within 72 hours after FB ingestion, and
blunt FB could be indications for Foley catheter-based FB removal.
What is new in the current study
$\begin{aligned} & \text { No research studies have investigated the factors, except for the time after FB ingestion, that affect the success of Foley } \\ & \text { catheter-based esophageal FB removal. This study establishes that longer training periods tend to increase the success } \\ & \text { rate of Foley catheter-based esophageal FB removal, albeit without statistical significance. }\end{aligned}$

\section{INTRODUCTION}

In children under the age of 5 years, foreign body (FB) ingestion is one of the leading causes of emergency department (ED) visits, and mostly comprises cases of unintentional ingestion that occurs at home. ${ }^{1}$ In the majority of cases, the ingested FB passes through the cervical esophagus and spontaneously advances through the gastrointestinal tract without complications. ${ }^{2}$ In approximately 5\% to $8 \%$ of cases, the ingested FB, depending on the type, could cause complications, such as obstruction, perforation, and bleeding in the gastrointestinal tract, and necessitate endoscopic or surgical intervention. ${ }^{3-5}$ In the case of worsening of symptoms, such as dyspnea, or non-likelihood of spontaneous FB expulsion (i.e., because of the FB's size or location), endoscopic removal proves indispensable. ${ }^{6}$ However, endoscopy is not always feasible in all hospitals, specifically for pediatric cases, and a disadvantage of the procedure is that it is cost and time intensive to prepare the required clinical personnel.' Thus, some emergency physicians use a Foley catheter to extract small and blunt FBs from the esophagus. ${ }^{8}$

Several studies have investigated the factors associated with Foley catheter-based esophageal FB removal methods, especially with an aim to increase the procedure's success rate. ${ }^{9,10}$ In the actual ED environments, these factors may differ.

This study aimed to identify factors associated with successful FB removal using a Foley catheter in the ED and to comparatively evaluate the differences with those reported in earlier studies.

\section{METHODS}

\section{Study design and population}

This retrospective, cross-sectional study enrolled pediatric patients who visited the EDs of Kyungpook National University Hospital (age 0-15 years) and the Kyungpook National University Chilgok Hospital (age 0-18 years) for esophageal FB impaction between
January 1, 2008 and December 31, 2018. This study protocol was approved by the institutional review board of the Kyungpook National University Chilgok Hospital (2020-02-010), and the approving authority waived the requirement for informed consent due to retrospective anonymized data analysis.

\section{Eligibility criteria}

Pediatric patients who visited the ED with an esophageal FB and underwent an attempted Foley catheter-based FB removal were eligible for study inclusion. The exclusion criteria were as follows: None of the patients removed FB using foley catheter were excluded from this study.

\section{Variables}

We collected the following data from a chart review of the patients' medical records: age, sex, symptoms; FB type, size, and location; size of the Foley catheter; complications during removal; duration between ingestion and removal; operator's training experience (years); sedation; successful removal; performing endoscopy for FB removal; and the patient's position during FB removal.

\section{Outcome}

This study determined the factors that were associated with successful removal of esophageal FBs using a Foley catheter.

\section{Extraction procedure}

Based on the esophageal location of the FB on X-ray, the position of the FB was categorized as (1) upper thoracic esophagus (from the upper esophageal sphincter to the tracheal bifurcation), (2) mid-thoracic esophagus (from the tracheal bifurcation to the midpoint between the tracheal bifurcation and the gastroesophageal junction), and (3) lower thoracic esophagus (from the midpoint between the tracheal bifurcation and gastroesophageal junction to the gastroesophageal junction). 
During FB removal, the patient was placed in the sitting or decubitus position; at the operator's discretion, an 8 to $20 \mathrm{Fr}$-sized Foley catheter was transorally inserted into the esophagus, similarly as in a Levin tube insertion. Based on the predetermined distance between the mouth and the $F B$, calculated from the radiography archive system of X-rays and, the Foley catheter's tip was advanced distally toward the FB. Then, the Foley catheter's balloon was inflated with 5 to $10 \mathrm{~mL}$ normal saline or air and slowly withdrawn; when the operator felt a resistance from the $F B$, the Foley catheter was extracted by using a wrist snap. Cooperative patients received preprocedural training to immediately spit out the FB when it fell into the mouth. In uncooperative infants, sedation and a mouthpiece were used as necessary, and the FB that was dislodged into the mouth from the esophagus was manually extracted by the operator's finger. When sedation was needed, midazolam, ketamine, or a combination of both was used with access to resuscitative equipment under monitoring. When Foley catheter-based FB removal failed or symptoms worsened, the FB was removed endoscopically. After successful FB removal, patients were discharged after ascertaining that there were no complications such as sign of airway obstruction, including dyspnea or hypoxia; signs of esophageal injury, such as hematemesis or bloody saliva; FB impaction in the nasopharynx; and persistent throat pain. Successful FB removal was defined as transoral extraction of the $F B$, whereas failure was defined as persistent esophageal $F B$ impaction, $F B$ movement into the stomach after a failed FB extraction attempt, failure to extract the FB despite several attempts, or endoscopic FB removal. If more than one operator attempted FB removal, successful or failed FB removal was analyzed based on the first operator's FB extraction attempts.

\section{Statistical analysis}

The independent t-test or Mann-Whitney U test was used to compare the differences between groups of the clinical characteristics. The differences in proportions between groups were compared using the chi-square or Fisher exact test. The chi-square test for trend analysis was performed to analyze the relationship between categorical data. To analyze the relationship between one dependent variable (successful FB removal) and one or more independent variables, linear regression analysis was performed. To exclude or control confounding factors, multiple linear regression was planned with the inclusion of clinically important variables and significant variables identified in the univariate regression analysis. Numerical data are presented as mean \pm standard deviation.

All statistical analyses were performed using the IBM SPSS Statistics ver. 21.0 (IBM Corp., Armonk, NY, USA). We considered $\mathrm{P}<0.05$ as statistically significant.

\section{RESULTS}

This study enrolled 43 participants (26 males [60.5\%] and $17 \mathrm{fe-}$ males [39.5\%]; mean age, $41 \pm 26$ [range, 9-100] months). The FB removal was successful in $81.4 \%$ (35/43) of patients, but failed in $18.6 \%$ (8/43) of patients; no complications associated with FB removal were reported (Table 1). No statistically significant difference between groups was observed in the age- and sex-stratified analyses of $F B$ removal ( $P=0.958$ and 0.692 , respectively).

With regard to the FB type and size, the successful removal rate was $81.3 \%, 85.7 \%, 80.0 \%$, and $100 \%$ for $24-\mathrm{mm} 100$ Korean won (KW) and old $10 \mathrm{KW}$ (issued before 2006), 22-mm $50 \mathrm{KW}$, 18-mm 10 KW (issued after 2007), and 27-mm 500 KW coins, respectively. Coins accounted for $74.4 \%$ of the overall cases of esophageal FB impaction. No statistically significant difference was observed in the $F B$ removal based on the $F B$ size $(P=0.599)$ (Fig. 1).

Furthermore, 86.0\% (37/43), 7.0\% (3/43), and 7.0\% (3/43) of FBs were impacted in the upper, middle, and lower esophagus with corresponding successful removal rates of $83.8 \%(31 / 37)$, $66.7 \%(2 / 3)$, and $66.7 \%(2 / 3)$, respectively. We observed no statistically significant difference in the success rate based on the FB location $(P=0.308)$. The median duration and interquartile range (IQR) between FB ingestion and removal was $2.5(0.5-48)$; IQR 1.75 hours and 3 (1-3); IQR 1.92 hours, respectively, in the successful and failed FB extraction groups, with no statistically significant difference $(P=0.146)$. Sedation was used in $34.9 \%$ (15/43) of cases, of which 73.3\% (11/15) achieved successful FB removal; in the $65.1 \%(28 / 43)$ of patients who did not receive sedation, 85.7\% (24/28) achieved successful removal. There was no statistically significant difference with regard to sedation $(P=0.419)$.

Based on the years of training experience of the operator, the success rate was 71.4\% (15/21), 88.9\% (16/18), and 100\% (4/4) for the first- and second-year residents, third- and fourth-year residents, and first- and second-year specialists, respectively. Of note, the success rate increased with the years of training, although the results were not significant $(P=0.088)$ (Fig. 2). A sitting position was achieved in $16.3 \%$ (7/43) of patients, of which $82.9 \%$ of extractions were successful; $80.6 \%$ of extractions in the decubitus position were successful; however, no statistically significant difference in the success rate was observed with regard to the position $(\mathrm{P}=1.000)$.

Based on the operator's preference, 8 to 20 Fr Foley catheters were used. However, there was no statistically significant betweengroup difference in the success rate with regard to the size of the Foley catheter $(\mathrm{P}=0.695)$ (Table 2$)$. As none of the variables showed 
Table 1. Patients' baseline characteristics

\begin{tabular}{|c|c|c|c|c|c|c|c|c|c|c|c|}
\hline Case & Removal & $\begin{array}{l}\text { Age } \\
(\mathrm{mo})\end{array}$ & Sex & Site & Sedation & $\begin{array}{c}\text { Training } \\
\text { years }\end{array}$ & $\begin{array}{l}\text { FB size } \\
(\mathrm{mm})\end{array}$ & $\begin{array}{l}\text { FB type } \\
\text { (coin: KW) }\end{array}$ & $\begin{array}{l}\text { Foley cathe- } \\
\text { ter size (Fr) }\end{array}$ & Position & $\begin{array}{l}\text { Time (swallowing } \\
\text { to removal, hr) }\end{array}$ \\
\hline 1 & $\mathrm{~F}$ & 66 & $M$ & $\mathrm{~L}$ & No & 1 & 24 & Coin (100) & 16 & Sitting & 3 \\
\hline 2 & $S$ & 13 & M & U & $S$ & 1 & 18 & Coin (10) & 16 & Decubitus & 3 \\
\hline 3 & $S$ & 60 & $\mathrm{~F}$ & U & No & 1 & 24 & Coin (100) & 18 & Decubitus & 3 \\
\hline 4 & $S$ & 96 & M & U & No & 1 & 27 & Coin (500) & 16 & Decubitus & 2 \\
\hline 5 & $S$ & 23 & M & U & No & 1 & 24 & Coin (100) & 16 & Decubitus & 3.5 \\
\hline 6 & $\mathrm{~F}$ & 37 & $M$ & U & No & 1 & 24 & Coin (100) & 16 & Decubitus & 1 \\
\hline 7 & $\mathrm{~F}$ & 50 & $\mathrm{~F}$ & U & $S$ & 1 & 24 & Coin (100) & 16 & Decubitus & 2 \\
\hline 8 & $S$ & 25 & $M$ & U & $S$ & 2 & 24 & Coin (100) & 18 & Decubitus & 2.5 \\
\hline 9 & $S$ & 27 & M & U & No & 2 & 22 & Coin (50) & 14 & Decubitus & 3.5 \\
\hline 10 & $\mathrm{~F}$ & 13 & $M$ & U & No & 2 & 25 & Button & 14 & Decubitus & 3 \\
\hline 11 & $S$ & 12 & $\mathrm{~F}$ & U & No & 2 & 20 & Pebble & 10 & Decubitus & 10.5 \\
\hline 12 & $S$ & 38 & $\mathrm{~F}$ & U & No & 2 & 22 & Coin (50) & 14 & Decubitus & 15.7 \\
\hline 13 & $S$ & 12 & $M$ & U & No & 2 & 18 & Coin (10) & 14 & Sitting & 20.8 \\
\hline 14 & $S$ & 11 & $M$ & U & No & 2 & 7 & Lego block & 14 & Decubitus & 2.2 \\
\hline 15 & $S$ & 39 & $\mathrm{~F}$ & $U$ & $S$ & 2 & 22 & Coin (50) & 14 & Decubitus & 4.7 \\
\hline 16 & $S$ & 27 & $M$ & U & $S$ & 2 & 24 & Coin (100) & 14 & Decubitus & 1.3 \\
\hline 17 & $S$ & 57 & $M$ & U & $S$ & 2 & 24 & Coin (100) & 16 & Decubitus & 4.2 \\
\hline 18 & $S$ & 89 & $M$ & U & No & 2 & 24 & Coin (100) & 18 & Decubitus & 2.5 \\
\hline 19 & $S$ & 53 & $\mathrm{~F}$ & $\mathrm{~L}$ & No & 2 & 22 & Coin (50) & 16 & Decubitus & 2.7 \\
\hline 20 & $\mathrm{~F}$ & 68 & $\mathrm{~F}$ & U & $S$ & 2 & 22 & Coin (50) & 16 & Decubitus & 1.5 \\
\hline 21 & $\mathrm{~F}$ & 12 & $M$ & U & $S$ & 2 & 18 & Coin (10) & 16 & Decubitus & 1 \\
\hline 22 & $S$ & 57 & $M$ & $M$ & $S$ & 3 & 24 & Coin (100) & 18 & Decubitus & 3.5 \\
\hline 23 & $S$ & 33 & $\mathrm{~F}$ & L & $S$ & 3 & 21 & Disk battery & 16 & Decubitus & 4 \\
\hline 24 & $S$ & 24 & $\mathrm{~F}$ & U & No & 3 & 24 & Coin (100) & 18 & Decubitus & 48 \\
\hline 25 & $S$ & 9 & $M$ & U & No & 3 & 13 & Metal bead & 16 & Decubitus & 3.8 \\
\hline 26 & $S$ & 14 & $\mathrm{~F}$ & U & No & 3 & 21 & Disk battery & 8 & Decubitus & 2.5 \\
\hline 27 & $\mathrm{~F}$ & 64 & $\mathrm{~F}$ & M & No & 3 & 30 & Heart-shaped Plastic toy & 14 & Decubitus & 3 \\
\hline 28 & $S$ & 12 & $\mathrm{~F}$ & U & No & 3 & 20 & Baduk stone & 14 & Decubitus & 2.3 \\
\hline 29 & $\mathrm{~S}$ & 36 & M & $U$ & $S$ & 3 & 24 & Coin (100) & 20 & Decubitus & 1 \\
\hline 30 & $S$ & 17 & M & $U$ & No & 3 & 20 & Baduk stone & 14 & Decubitus & 21.5 \\
\hline 31 & $\mathrm{~F}$ & 22 & $\mathrm{~F}$ & U & $S$ & 3 & 15 & Lego block & 16 & Decubitus & 3 \\
\hline 32 & $S$ & 87 & M & U & $S$ & 3 & 27 & Coin (500) & 20 & Decubitus & 1 \\
\hline 33 & $S$ & 100 & M & M & No & 3 & 21 & Baduk stone & 16 & Decubitus & 1.8 \\
\hline 34 & $S$ & 66 & M & U & No & 3 & 24 & Coin (100) & 18 & Sitting & 3.2 \\
\hline 35 & $S$ & 76 & $M$ & U & No & 3 & 27 & Coin (500) & 16 & Decubitus & 3.3 \\
\hline 36 & $S$ & 41 & $M$ & U & No & 3 & 24 & Coin (10) & 16 & Decubitus & 3.5 \\
\hline 37 & $S$ & 77 & $M$ & U & No & 3 & 24 & Coin (100) & 16 & Decubitus & 1.3 \\
\hline 38 & $S$ & 23 & $\mathrm{~F}$ & U & No & 3 & 22 & Coin (50) & 16 & Decubitus & 1.2 \\
\hline 39 & $S$ & 42 & $\mathrm{~F}$ & U & $S$ & 4 & 27 & Coin (500) & 16 & Sitting & 4.3 \\
\hline 40 & $S$ & 13 & $M$ & U & No & 5 & 18 & Coin (10) & 16 & Sitting & 0.8 \\
\hline 41 & $S$ & 73 & $\mathrm{~F}$ & U & $S$ & 5 & 27 & Coin (500) & 18 & Sitting & 2.7 \\
\hline 42 & $S$ & 32 & $M$ & U & No & 5 & 22 & Coin (50) & 16 & Sitting & 2.7 \\
\hline 43 & $S$ & 19 & $\mathrm{~F}$ & U & No & 6 & 24 & Coin (100) & 16 & Decubitus & 0.5 \\
\hline
\end{tabular}

FB, foreign body; KW, Korean won; L, lower esophagus; U, upper esophagus; $M$, mid-esophagus; $F$, failure; $S$, Success.

statistical significance in the univariate regression analysis, the planned multivariate linear regression analysis could not be conducted.

\section{DISCUSSION}

Esophageal FB impaction is common in infants and children younger than 5 years. The conventional method of esophageal FB extraction using a Foley catheter can be successfully accomplished 


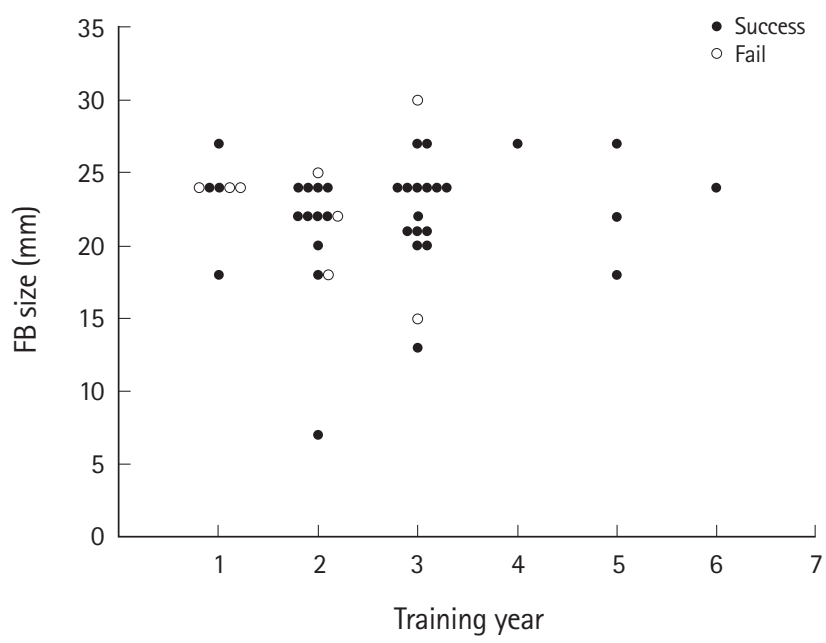

Fig. 1. The success rate of Foley catheter-based foreign body (FB) removal stratified by the FB size according to the number of training years.

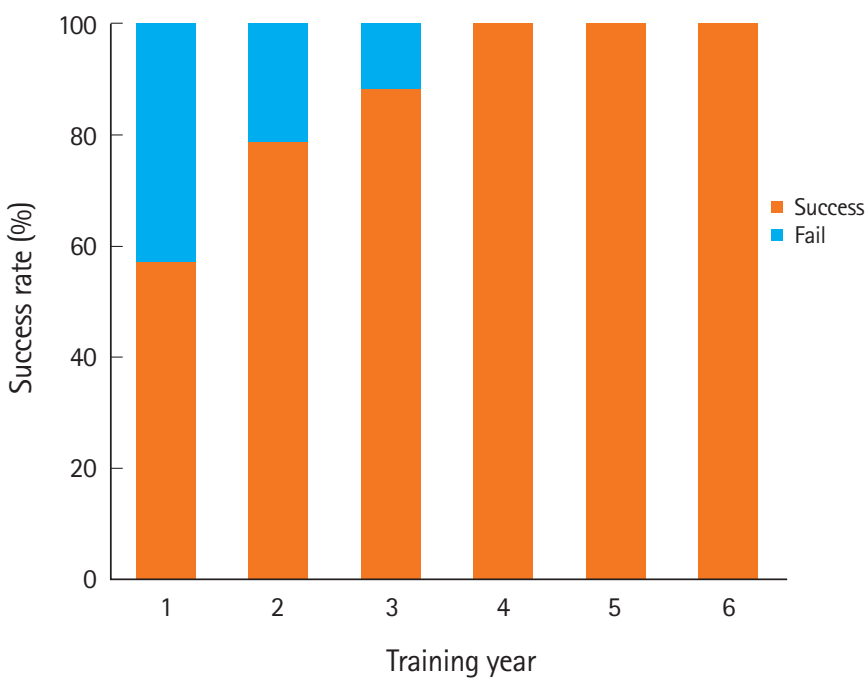

Fig. 2. The success rate of foreign body removal using a Foley catheter according to the number of training years.

by experienced practitioners. Thus, if immediate endoscopic FB removal is unfeasible, blunt FBs can be removed using a Foley catheter. Endoscopic esophageal FB removal remains the gold standard, although Foley catheter-based FB extraction has been used selectively for decades since the late 1960s and has some advantages, such as faster removal, over endoscopy. Studies comparing the time efficiency of FB removal using a Foley catheter and an endoscope found that the Foley catheter-based removal was faster (mean time $2.0 \pm 1.1$ vs. $18.1 \pm 13.7$ hours $^{9}$ and $0.70 \pm 0.28$ vs. $5.96 \pm 2.22$ hours, $^{10}$ respectively).

The disk battery is one of the most dangerous FBs in the esophagus that needs rapid, emergent removal. The intraesophageal leakage of battery liquid can cause caustic injury within 1 hour,
Table 2. Comparison of the characteristics of the successful and failed FB removal groups

\begin{tabular}{|c|c|c|c|}
\hline & $\begin{array}{l}\text { Successful FB } \\
\text { removal group } \\
\quad(n=35)\end{array}$ & $\begin{array}{l}\text { Failed FB } \\
\text { removal group } \\
(n=8)\end{array}$ & P-value \\
\hline Age (mo) & $40.9 \pm 27.5$ & $41.5 \pm 23.8$ & $0.958^{\mathrm{a})}$ \\
\hline Sex & & & $0.692^{\mathrm{b})}$ \\
\hline Male & $22(62.9)$ & $4(50.0)$ & \\
\hline Female & $13(37.1)$ & $4(50.0)$ & \\
\hline Esophageal site & & & $0.308^{b)}$ \\
\hline Upper thoracic & $31(88.6)$ & $6(75.0)$ & \\
\hline Mid-thoracic & $2(5.7)$ & $1(12.5)$ & \\
\hline Lower thoracic & $2(5.7)$ & $1(12.5)$ & \\
\hline Sedation & & & $0.419^{b)}$ \\
\hline Sedated & $11(31.4)$ & $4(50.0)$ & \\
\hline Non-sedated & $24(68.6)$ & $4(50.0)$ & \\
\hline Training years & & & $0.088^{\mathrm{c})}$ \\
\hline $1-2$ & $15(42.9)$ & $6(75.0)$ & \\
\hline $3-4$ & $16(45.7)$ & $2(25.0)$ & \\
\hline $5-6$ & $4(11.4)$ & $0(0)$ & \\
\hline Foley catheter size $(\mathrm{Fr})$ & & & $0.695^{b)}$ \\
\hline 8 & $1(2.9)$ & $0(0)$ & \\
\hline 10 & $1(2.9)$ & $0(0)$ & \\
\hline 14 & $8(22.9)$ & $2(25.0)$ & \\
\hline 16 & $16(45.7)$ & $6(75.0)$ & \\
\hline 18 & $7(20.0)$ & $0(0)$ & \\
\hline 20 & $2(5.7)$ & $0(0)$ & \\
\hline Position & & & $1.000^{b)}$ \\
\hline Sitting & $6(17.1)$ & $1(12.5)$ & \\
\hline Decubitus & 29 (82.9) & $7(87.5)$ & \\
\hline $\begin{array}{l}\text { Time (swallowing to } \\
\text { removal, hr) }\end{array}$ & $5.58 \pm 8.93$ & $2.19 \pm 0.92$ & $0.146^{a)}$ \\
\hline $\mathrm{FB}$ size $(\mathrm{mm})$ & & & $0.599^{c)}$ \\
\hline 7 & $1(2.9)$ & $0(0)$ & \\
\hline 13 & $1(2.9)$ & $0(0)$ & \\
\hline 15 & $0(0)$ & $1(12.5)$ & \\
\hline 18 & $3(8.6)$ & $1(12.5)$ & \\
\hline 20 & $3(8.6)$ & $0(0)$ & \\
\hline 21 & $3(8.6)$ & $0(0)$ & \\
\hline 22 & $6(17.1)$ & $1(12.5)$ & \\
\hline 24 & 13 (37.1) & $3(37.5)$ & \\
\hline 25 & $0(0)$ & $1(12.5)$ & \\
\hline 27 & $5(14.3)$ & $0(0)$ & \\
\hline 30 & $0(0)$ & $1(12.5)$ & \\
\hline
\end{tabular}

Values are presented as mean \pm stadard deviation or number $(\%)$.

$F B$, foreign body.

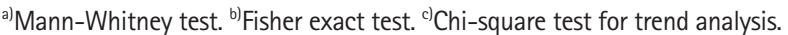

full thickness damage to the esophagus in 4 hours, and esophageal perforation in 6 hours, in addition to the complications of esophageal stenosis, and even lead to death. ${ }^{11,12}$ Therefore, removal of disk battery impactions with a Foley catheter must be considered as soon as possible, within 2 hours of ingestion. ${ }^{13}$ In 
this study, although the 2-hour limit following the disk battery ingestion had elapsed in two cases, the Foley catheter-based FB extraction was successful. In both cases, a high risk of esophageal perforation was anticipated with the time required to prepare for endoscopy. Thus, FB removal using Foley catheter was performed with the guardian's informed consent after a sufficient explanation of the side effects. In both cases, however, ulcers without perforation were confirmed using an endoscope and esophagogram after FB removal; thus, these two patients needed regular outpatient follow-up.

Indications for a Foley catheter-based removal of an esophageal FB include radiopacity, blunt or round shape, impaction of the $F B$ in the upper or mid-esophagus and ingestion within 24 to 72 hours. ${ }^{6,14,15}$ In some studies, upper esophageal FBs accounted for $63 \%$ to $86 \%$ of all esophageal FBs. ${ }^{16,17}$ In this study, $86 \%$ (37/43) of patients had FB impaction in the upper esophagus. We have experience with the removal of a lower esophageal FB using a Foley catheter; however, the closer the FB gets to the lower esophageal sphincter, the more likely it is to pass through the gastrointestinal tract just by drinking water or eating food. ${ }^{18}$

There is a difference in the procedure success rates depending on the mean time from FB ingestion to removal; however, this time differs in the 24 to 72 hours range among studies. For example, Conner ${ }^{15}$ reported that esophageal edema and inflammation worsened after 24 hours, whereas Schunk et al. ${ }^{14}$ found a significant difference in the success rate of esophageal FB removal based on the 72-hour cutoff point. In this study, we observed no statistically significant difference in the success rate based on the mean duration between $F B$ ingestion and removal $(P=0.146)$. Contraindications for the Foley catheter-based $F B$ removal include sharp FBs, multiple FBs, symptoms of upper airway obstruction such as dyspnea, radiolucent FBs, anatomical esophageal abnormalities, or a history of surgery. ${ }^{10}$ In such cases, immediate endoscopic FB removal is the gold standard of care. If the FB ingestion time is unknown, the edema of the esophageal wall and tracheal stenosis on the lateral view chest $\mathrm{X}$-ray are crucial findings, and these findings are advantageous to plan immediate endoscopic FB removal rather than using a Foley catheter. ${ }^{19}$

There was no complication in the cases included in this study. However, complication rates of $0 \%$ to $2 \%$ with Foley catheterbased esophageal FB removal have been reported when the indications are well maintained..$^{20}$ In a study of FB removal in 2,500 cases, Campbell and Condon ${ }^{21}$ reported reversible hypoxia in only one case, whereas Schunk et al. ${ }^{14}$ reported only four cases of esophageal laceration and mediastinitis from among 415 cases of Foley catheter-based FB removal. In this study, we did not use fluoroscopy based on the reports from previous studies. In esoph- ageal FB removal using a Foley catheter without fluoroscopy, the success rate was 93.7\% in 302 cases and 91\% in 415 cases without major complications. ${ }^{14,22}$

The Foley catheter-based FB removal is not a difficult technique, and physicians without experience can easily learn it by merely observing the procedure a few times. Reportedly, one or two observations after a simple training session can increase the success rate, with limited failures..$^{10}$ In addition, operators, even if they are junior residents, with prior successful experience demonstrated a high success rate. ${ }^{9}$ In the absence of adequate opportunities to provide practical experience, simulation training using videos, such as via YouTube, is useful. ${ }^{23-26}$ In our hospital, junior residents who have no experience in the Foley catheter-based FB extraction procedure are required to watch the procedure and have a simulation training using a YouTube video before the procedure if a patient with an esophageal FB visits the ED. Eventually, a successful experience can lead to repeated successes. In this study, longer training periods tended to increase the success rate of FB removal, although there was no significant difference. Confidence in the procedure undertaken by senior physicians, experience, observation of the Foley catheter method during the training period, and skillful patient control could have contributed to the success rate.

This study has some limitations that are worth acknowledging. First, the planned multivariate linear regression analysis was not possible because none of the variables showed statistical significance in the univariate regression analysis. This is attributed to an insufficient number of cases; therefore, larger sample future studies are needed to accumulate evidence to validate the findings presented herein. Second, the number of previous removal experiences of each operator was unknown. Third, the number of FB removal attempts were not defined. Therefore, further studies with large sample sizes and a more detailed data analysis of the medical records are warranted in the future.

In summary, longer training periods tend to increase the success rate of FB removal, although there was no significant difference based on the training periods. Foley catheter-based esophageal FB removal may be a practical and useful approach in environments without immediate access to pediatric endoscopy for esophageal FB removal.

\section{CONFLICT OF INTEREST}

No potential conflict of interest relevant to this article was reported. 


\section{REFERENCES}

1. Gummin DD, Mowry JB, Spyker DA, et al. 2018 Annual report of the American Association of Poison Control Centers' National Poison Data System (NPDS): 36th annual report. Clin Toxicol (Phila) 2019;57:1220-413.

2. Seo JK. Endoscopic management of gastrointestinal foreign bodies in children: a clinical practice guideline. Korean J Pediatr Gastroenterol Nutr 2007;10:64-9.

3. Singh B, Kantu M, Har-El G, Lucente FE. Complications associated with 327 foreign bodies of the pharynx, larynx, and esophagus. Ann Otol Rhinol Laryngol 1997;106:301-4.

4. Loh KS, Tan LK, Smith JD, Yeoh KH, Dong F. Complications of foreign bodies in the esophagus. Otolaryngol Head Neck Surg 2000;123:613-6.

5. Sink JR, Kitsko DJ, Mehta DK, Georg MW, Simons JP. Diagnosis of pediatric foreign body ingestion: clinical presentation, physical examination, and radiologic findings. Ann Otol Rhinol Laryngol 2016;125:342-50.

6. Choe JY, Choe BH. Foreign body removal in children using foley catheter or magnet tube from gastrointestinal tract. Pediatr Gastroenterol Hepatol Nutr 2019;22:132-41.

7. Kim JO, Hong EH, Choe BH, et al. Comparison of endoscopic removal of disk batteries in children. Korean J Pediatr Gastroenterol Nutr 2007;10:147-56.

8. Kramer RE, Lerner DG, Lin T, et al. Management of ingested foreign bodies in children: a clinical report of the NASPGHAN Endoscopy Committee. J Pediatr Gastroenterol Nutr 2015;60: 562-74.

9. Kang JH, Jung HJ, Suh JK, et al. Feasibility of foley catheter prior to endoscopy for the removal of esophageal coin in children. Korean J Pediatr Gastroenterol Nutr $2011 ; 14: 251-7$.

10. Kim GW, Kim SY, Lee CC, Kim C, Jung YS. Removal of esophageal blunt foreign bodies by using a Foley balloon catheter in the emergency department. J Korean Soc Emerg Med 2001; 12:359-68.

11. Rossi A, Vignola $S$, Nason $F$, et al. Safe energy source in battery-operated toys for children. J Pediatr Gastroenterol Nutr 2017;65:496-9.

12. Schreiner I, Bonadio W. Disk battery ingestion in a toddler: less than meets the eye. J Emerg Med 2017;52:863-6.
13. Tintinalli JE. Tintinalli's emergency medicine: a comprehensive study guide. 8th ed. New York, NY: McGraw-Hill Education; 2016.

14. Schunk JE, Harrison AM, Corneli HM, Nixon GW. Fluoroscopic foley catheter removal of esophageal foreign bodies in children: experience with 415 episodes. Pediatrics 1994;94:70914.

15. Conners GP. A literature-based comparison of three methods of pediatric esophageal coin removal. Pediatr Emerg Care 1997; 13:154-7.

16. Webb WA. Management of foreign bodies of the upper gastrointestinal tract. Gastroenterology 1988;94:204-16.

17. Cho WR, Park BW, Yoo MJ, Seok SR, Kim SG, Kim MG. Esophageal foreign body (coin) removal using Foley's catheter. Korean J Otorhinolaryngol-Head Neck Surg 1999;42:1035-40.

18. Conners GP, Chamberlain JM, Ochsenschlager DW. Foley catheter and esophageal foreign bodies. Pediatrics 1995;96:791.

19. Harned RK 2nd, Strain JD, Hay TC, Douglas MR. Esophageal foreign bodies: safety and efficacy of Foley catheter extraction of coins. AJR Am J Roentgenol 1997;168:443-6.

20. Stack LB, Munter DW. Foreign bodies in the gastrointestinal tract. Emerg Med Clin North Am 1996;14:493-521.

21. Campbell JB, Condon VR. Catheter removal of blunt esophageal foreign bodies in children: survey of the Society for Pediatric Radiology. Pediatr Radiol 1989;19:361-5.

22. Agarwala S, Bhatnagar V, Mitra DK. Coins can be safely removed from the esophagus by Foley's catheter without fluoroscopic control. Indian Pediatr 1996;33:109-11.

23. Lopreiato JO, Sawyer T. Simulation-based medical education in pediatrics. Acad Pediatr 2015;15:134-42.

24. Okuda Y, Bryson EO, DeMaria S Jr, et al. The utility of simulation in medical education: what is the evidence? Mt Sinai J Med 2009;76:330-43.

25. Sacchetti A. Esophageal coin extraction [Internet]. San Bruno, CA:YouTube; 2015 [cited 2020 Jun 10]. Available from: https: //youtu.be/k9cG1T20kIO.

26. SurgMedia. Foreign body retrieval with Foley catheter: unusual management of a usual presentation [Internet]. San Bruno, CA: YouTube; 2018 [cited 2020 Jun 10]. Available from: https: //youtu.be/6UP20g5390Y. 